\title{
Anti-Inflammatory and Antimicrobial Activities of Compounds Isolated from Distichochlamys benenica
}

\author{
Ty Viet Pham $\left(\mathbb{D},{ }^{1}\right.$ Hanh Nhu Thi Hoang $\mathbb{D},{ }^{2}$ Hoai Thi Nguyen $\mathbb{D}^{,},{ }^{3}$ Hien Minh Nguyen $\left(\mathbb{D},{ }^{4}\right.$ \\ Cong Thang Huynh, ${ }^{4}$ Thien Y Vu $\mathbb{D}^{4},{ }^{4}$ Anh Thu Do $\mathbb{D},{ }^{5}$ Nguyen Hoai Nguyen $\mathbb{D}^{6}{ }^{6}$ \\ and Bich Hang Do ${ }^{4}$
}

\author{
${ }^{1}$ Faculty of Chemistry, University of Education, Hue University, 34 Le Loi, Hue City, Vietnam \\ ${ }^{2}$ Faculty of Engineering and Food Technology, Hue University of Agriculture and Forestry, Hue University, 102 Phung Hung, \\ Hue City, Vietnam \\ ${ }^{3}$ Faculty of Pharmacy, University of Medicine and Pharmacy, Hue University, 06 Ngo Quyen, Hue City, Vietnam \\ ${ }^{4}$ Faculty of Pharmacy, Ton Duc Thang University, Ho Chi Minh City, Vietnam \\ ${ }^{5}$ English Faculty, Foreign Trade University-Ho Chi Minh City Campus, Vietnam \\ ${ }^{6}$ Faculty of Biotechnology, Ho Chi Minh City Open University, Ho Chi Minh City, Vietnam
}

Correspondence should be addressed to Bich Hang Do; dobichhang@tdtu.edu.vn

Received 5 October 2020; Revised 12 March 2021; Accepted 19 March 2021; Published 7 April 2021

Academic Editor: Ziqing Li

Copyright (C) 2021 Ty Viet Pham et al. This is an open access article distributed under the Creative Commons Attribution License, which permits unrestricted use, distribution, and reproduction in any medium, provided the original work is properly cited.

\begin{abstract}
Distichochlamys benenica is a native black ginger that grows in Vietnam. In point of fact, there is limitation of available information in the literature making mention of the chemical constituents and bioactive properties of this plant. This study is aimed at isolating trans-o-coumaric acid (1), trans-cinnamic acid (2), and borneol (3) from the rhizomes of D. benenica Q.B.Nguyen \& Škorničk and evaluate the anti-inflammatory and antimicrobial activities of 1-3 using the carrageenan paw edema model and the dilution broth method, respectively. This revealed that $\mathbf{1}$ was as effective as diclofenac in reducing the intensity of the edema development. The in silico research showed that the activity of $\mathbf{1}$ might be derived from inhibiting COX-2 by generating h-bonds at the positions of Arg 120, Tyr 355, and Arg 513 residues. The antimicrobial activities against Gram-positive strains (Staphylococcus aureus and Bacillus subtilis) were comparable, with the minimum inhibitory concentrations ranging from 1.52 to $3.37 \mathrm{mM}$. This is the first study of the bioactivity of compounds isolated from $D$. benenica Q.B.Nguyen \& Škorničk. Our results suggest that 1 may be a nature-derived compound which demonstrates the anti-inflammatory properties and inhibit the proliferation of several Gram-positive bacteria.
\end{abstract}

\section{Introduction}

Inflammation is an immune response to pathogen invasion that is mediated by the release of mediators including cytokines, histamine, prostaglandin, and leukotrienes, as well as enhanced vascular permeability, leading to the recruitment of leukocytes to the site of inflammation, resulting in the clearing of pathogens $[1,2]$. Nevertheless, if inflammation is not regulated properly, it may cause different diseases including autoimmune, neurodegenerative, and cardiovascular diseases, cancer, diabetes mellitus, and diseases [2-4]. Hence, compounds which enable amelioration of the inflammation can enhance the efficiency in treating those diseases. Many plant extracts and their isolated compounds are effective at reducing inflammatory mediators, recruiting leukocytes, moderating swelling, and alleviating inflammatory symptoms [5-7]. Additionally, plants are also valuable sources of antimicrobials $[8$, 9]. With the development of antibiotic resistance, alternative antimicrobial compounds are urgently needed.

The genus Distichochlamys (Zingiberaceae) was discovered in Bach Ma National Park, Thua Thien Hue Province, Vietnam, in 1995 by M. F. Newman [10]. Traditionally, this genus is used by ethnic Pako as food and as medicine for abdominal pain, blood coagulation, wound healing, and pus 
removal. Four congenerics have been identified: D. citrea M.F. Newman, D. rubrostriata W.J. Kress and Rehse, D. benenica Q.B. Nguyen \& Škorničk, and D. orlowii K. Larsen and M.F. Newman. The extracts of Zingiberaceae possessed antioxidant, antimicrobial, and anti-inflammatory properties [11-14]. Although the chemical compositions of the Distichochlamys genus have been investigated [15-17], few studies have examined the bioactivity. One study mentioned that the essential oil from the rhizomes of D. benenica possesses acetylcholinesterase activity [18].

Cinnamic acid, an aromatic acid isolated from natural sources, holds various bioactivities including antidiabetes, anti-inflammatory, antityrosinase, antimicrobial, antioxidant, and anticancer properties [19-21]. Coumaric acid is a hydroxy derivative of cinnamic acid with three isomers: $o$-, $m$-, and $p$-coumaric acids. The most widely studied is $p$-coumaric, which has anti-inflammatory, antioxidant, antibacterial, anticancer, and diabetes mitigation effects [22-25]. Trans-o-coumaric acid was demonstrated to have antimicrobial and antifungal abilities [26]. Borneol is a naturally occurring bicyclic monoterpenoid that possesses antimicrobial and anti-inflammatory properties and increases blood-brain permeability, enhancing the enhancement of drug delivery to the central nervous system [27-30].

In this study, we isolated trans-o-coumaric acid (1) [26], trans-cinnamic acid (2) [31], and borneol (3) [32] from the rhizomes of $D$. benenica Q.B.Nguyen \& Škorničk, elucidated their structures, and investigated their bioactive properties. For the first time, the bioactivities of compounds isolated from $D$. benenica have been investigated. The anti-inflammatory activity was examined in vivo using a carrageenan-induced edema assay, and the antimicrobial activity was evaluated using the broth dilution test.

\section{Materials and Methods}

2.1. Materials. Diclofenac, carrageenan, and solvents such as $n$-hexane, chloroform, acetone, ethyl acetate, and methanol were obtained from Sigma-Aldrich (St Louis, MO, USA). Mueller-Hinton Broth was purchased from Thermo Fisher Scientific (Massachusetts, USA). Silica gel (60 N, spherical, neutral, 40-50 $\mu \mathrm{m}$ ) was obtained from Kanto Chemical Co., Inc. (Tokyo, Japan). Plethysmometer was purchased from Panlab, Havard Apparatus. Infrared spectra were recorded on an IR Prestige-21 spectrometer (Shimadzu, Kyoto, Japan). NMR spectra were recorded using a Bruker Avance 500 spectrometer (Bruker, MA, USA), with TMS as an internal reference. HRESIMS data were measured on an Agilent 6530 Accurate-Mass spectrometer (Agilent, CA, USA). Analytical TLC was performed on precoated silica gel $60 \mathrm{~F}_{254}$ and RP-18 $\mathrm{F}_{254}$ plates $(0.25$ or $0.50 \mathrm{~mm}$ thickness, Merck KGaA, Darmstadt, Germany). Spots were detected under UV radiation ( $254 \mathrm{~nm}$ and $365 \mathrm{~nm}$ ) and by spraying the plates with $10 \%$ sulfuric acid followed by heating with a heat gun.

D. benenica Q.B.Nguyen \& Škorničk was collected in January 2020 at Quang Nam province and identified by Hue University of Agriculture and Forestry. A voucher specimen (DB1) was deposited in the Faculty of Chemistry at the Hue University of Education.

\subsection{Methods}

2.2.1. The Preparation of Compounds. The rhizomes of $D$. benenica were dried and ground before applying to the extraction process. The rhizomes $(1.2 \mathrm{~kg})$ of $D$. benenica were powdered and extracted with $n$-hexane $(2.5 \mathrm{~L} \times 5$ cycles $)$, chloroform $(2.0 \mathrm{~L} \times 5$ cycles $)$, and methanol $(2.0 \mathrm{~L} \times 4$ cycles $)$ at room temperature. The supernatants were evaporated at under $40^{\circ} \mathrm{C}$ in vacuo to obtain three extracts including crude $n$-hexane (DBH, $80.0 \mathrm{~g}$ ), crude chloroform (DBC, $85.0 \mathrm{~g}$ ), and crude methanol (DBM, $105.0 \mathrm{~g}$ ), respectively. The DBH extract $(80.0 \mathrm{~g})$ was applied to column chromatography on silica gel and subsequently eluted with a gradient system of $n$-hexane-acetone $(100: 0,40: 1,20: 1$, and $10: 1, v / v, 2.0 \mathrm{~L}$ each) to obtain 4 fractions $(\mathrm{H} 1-\mathrm{H} 4)$. Fraction $\mathrm{H} 3(5.0 \mathrm{~g})$ was chromatographed on a silica gel column eluted with $n$ hexane-acetone $(95: 5, v / v)$ to yield borneol (3) $(21.8 \mathrm{mg})$. Similarly, fraction H4 (7.5 g) was chromatographed on a silica gel column eluted with $n$-hexane-EtOAc $(90: 10, v / v)$ to give trans-cinnamic acid (2) $(16.9 \mathrm{mg})$ and trans- $O$-coumaric acid (1) (13.7 mg), respectively. Compounds 1-3 were dissolved in DMSO to the concentration of $100 \mathrm{mg} / \mathrm{mL}$ then diluted into $0.9 \% \mathrm{NaCl}$ to the tested concentrations. The samples were filtered through $0.4 \mu \mathrm{m}$ filters before use.

2.2.2. Experimental Mice. Swiss albino mice of 6-8 weeks of age $(18 \pm 2 \mathrm{~g})$ were obtained from Pasteur Institute, Ho Chi Minh City, Vietnam. They were housed under standard husbandry conditions with a $12 \mathrm{~h}$ light-dark cycle for at least 1 week to acclimate with the laboratory environment. They were supplied ad libitum with standard chow and distilled water. The healthy mice were used in the experiments. The experimental procedure was strictly complied with the Declaration of Helsinki (1964).

2.2.3. The Anti-Inflammation Assay. The anti-inflammatory ability of 1-3 was evaluated using the carrageenan-induced paw edema method following the previously described protocol [33]. The mice were divided into 5 groups of 6 mice each. Mice were intraperitoneally pretreated with 1-3 at a dose of $20 \mathrm{mg} / \mathrm{kg}$. Mice treated with saline $(0.9 \% \mathrm{w} / \mathrm{v} \mathrm{NaCl}, \mathrm{p} . \mathrm{o})$ and diclofenac $(10 \mathrm{mg} / \mathrm{kg}, \mathrm{p} . \mathrm{o})$ were used as negative and positive controls, respectively. One hour later, mice were subplantar injected with $40 \mu \mathrm{L} 1 \%$ carrageenan (suspended in saline) into the right hind paw to stimulate the edema. The paw volume was measured using a plethysmometer before carrageenan treatment $\left(C_{0}\right)$ and after carrageenan injection at selected time intervals $1,2,3$, and $4 \mathrm{~h}\left(C_{t}\right)$.

The anti-inflammatory activity was calculated using the following equation:

$$
\text { \%Inhibition }=100 \times \frac{\left(\left(C_{t}-C_{0}\right)_{\text {control }}-\left(C_{t}-C_{0}\right)_{\text {treated }}\right)}{\left(C_{t}-C_{0}\right)_{\text {control }}} \text {, }
$$

where $\left(C_{t}-C_{0}\right)_{\text {control }}$ is the difference of the paw volume in the negative control group, and $\left(C_{t}-C_{0}\right)_{\text {treated }}$ is the difference of the paw volume in the tested or positive control groups. 
The highest anti-inflammatory compound was confirmed further at different concentrations. The protocol is similar to the aforementioned one. Briefly, the mice were peritoneally injected with the compound at dosages of 5,10 , and $20 \mathrm{mg} / \mathrm{kg}$ $1 \mathrm{~h}$ before injection of carrageenan into the right hind paw. Mice treated with saline $(0.9 \% \mathrm{w} / \mathrm{v} \mathrm{NaCl}, \mathrm{p} . \mathrm{o})$ and diclofenac $(10 \mathrm{mg} / \mathrm{kg}$, p.o) were used as negative and positive controls, respectively. The volume of the paw was assessed before $\left(C_{0}\right)$ and after carrageenan injection $\left(C_{t}\right)$ hourly until $4 \mathrm{~h}$ using a plethysmometer. The anti-inflammatory activity was determined following the aforementioned equation.

After $4 \mathrm{~h}$ of carrageenan treatment, the inflamed paws were pictured to compare the change in appearance of treated groups.

2.2.4. The Antimicrobial Assay. The antimicrobial activity of 1-3 was determined using the broth microdilution method [34]. The test was performed using sterile polystyrene 96well plates. $100 \mu \mathrm{L}$ of autoclaved Muller-Hinton Broth supplemented with different concentrations of 1-3 (1, 0.5, 0.25, $0.125,0.0625$, and $0.03125 \mathrm{mg} / \mathrm{mL}$ ) was added into each well. Subsequently, $5 \mu \mathrm{L}$ of the bacteria including Staphylococcus aureus, Bacillus subtilis, Pseudomonas aeruginosa, and Escherichia coli at the concentration of approximately $10^{8} \mathrm{CFU} / \mathrm{mL}$ was added. The plate was shaken and incubated at $37^{\circ} \mathrm{C}$ for $24 \mathrm{~h} .0 .1 \%$ DMSO was used as a negative control, and ciprofloxacin was used as a positive control. Minimum inhibitory concentration (MIC) was defined as the lowest concentration of the extract at which the microorganisms showed no visible growth.

2.2.5. Ligand Docking. The two targeted proteins used in ligand docking are cyclooxygenase 1 (COX-1) and cyclooxygenase 2 (COX-2), which are the two main proteins responsible for the inflammatory process. The published crystal structures of COX-1 (PDB 2OYU) and COX-2 (PDB 4COX) were imported and prepared by Maestro software (Schrödinger Release 2020-3). The general procedure of the Protein Preparation Wizard [35] was used to assign bond orders, remove waters, generate het states using Epik, optimize the h-bond, and minimize the protein with the OPLS3e force field. The grid box for the docking job was defined by centroid of native ligands in two proteins expanded to $20 \AA$ in a three-dimensional space.

2.2.6. Molecular Dynamics Simulations. Three molecules 1, 2, 3 and the reference drug diclofenac were created and prepared by Ligprep [36] to obtain possible ionization states at physiological $\mathrm{pH}=7 \pm 2$. These compounds and the native ligand of crystallized protein were then docked to the grid box of two proteins by using two successive methods Glide [37] SP (standard precision) and XP (extra precision). The refined XP top scores were used to feed the MM-GBSA [38] calculations (molecular mechanics/generalized Born and surface area method) with the VSGB solvation model and same force field. The relative free binding energy values obtained from these calculations are used to compare the inhibition capacity of 1-3 with reference standards. From there, the system set-up of molecular dynamics simulations was built for

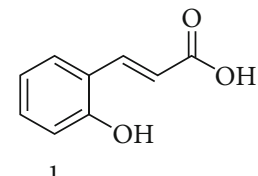

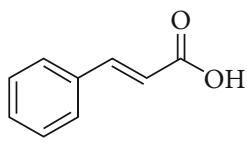

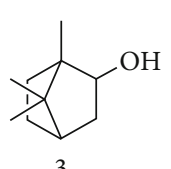

3
FIgURE 1: Structures of 1-3 isolated from the rhizomes of $D$. benenica.

docked ligands with COX-1 and COX-2 by using Desmond [39]. The solvent model was predefined with SPC, and the force field was kept unchanged OPLS3e. The total simulation time lasted $50 \mathrm{~ns}$ for each system, and 50 ps was set to trajectory recording intervals. The system energy was 1.2 , and the ensemble class used was NPT at $300.0 \mathrm{~K}$ temperature and at 1.01325 bar pressure. The relax model system was a default option before simulations.

2.2.7. Statistical Analysis. All data are presented as the mean \pm standard error (SE). Statistical analyses were performed using the SPSS statistical software program (SPSS, version 18.0, Chicago, IL). A Student's $t$-test was used to determine the statistical significance of group means. All tests were two sided, and $p$ values less than 0.05 were considered statistically significant.

\section{Results}

3.1. The Determination of Isolated Compounds. Compounds 1-3 were isolated from $n$-hexane extract of $D$. benenica Q. B. Nguyen \& Škorničk rhizome. Compounds 1 and 2 are white crystalline powder with the molecular formulas of $\mathrm{C}_{9} \mathrm{H}_{8} \mathrm{O}_{3}$ and $\mathrm{C}_{9} \mathrm{H}_{8} \mathrm{O}_{2}$, respectively. Compound 3 is whitecolored lump-solid with the molecular formula of $\mathrm{C}_{10} \mathrm{H}_{18} \mathrm{O}$. The data values of IR, HRESIMS, ${ }^{1} \mathrm{H}-\mathrm{NMR}$, and ${ }^{13} \mathrm{C}$-NMR of 1-3 and chemical structures of 1-3 are described in Figure 1 and in Supplementary S1-S22.

trans-o-coumaric acid (1): IR (KBr) $v_{\max }\left(\mathrm{cm}^{-1}\right): 3456$, $3063,3028,2982,1682,1628,1420,1312,1285,1223,980$, 941, 914, 768, 706; HRESIMS $\mathrm{m} / \mathrm{z} 163.0376[\mathrm{M}-\mathrm{H}]]^{-} ;{ }^{1} \mathrm{H}-$ NMR $(500 \mathrm{MHz}, \mathrm{MeOD}): \delta 7.99(1 \mathrm{H}, \mathrm{d}, J=16.0 \mathrm{~Hz}, \mathrm{H}-3)$, $7.49\left(1 \mathrm{H}, \mathrm{d}, J=1.0,8.0 \mathrm{~Hz}, \mathrm{H}-6^{\prime}\right), 7.22(1 \mathrm{H}, \mathrm{td}, J=1.0$, $\left.8.0 \mathrm{~Hz}, \mathrm{H}-4^{\prime}\right), 6.86\left(1 \mathrm{H}, \mathrm{d}, J=8.0 \mathrm{~Hz}, \mathrm{H}-3^{\prime}\right), 6.85(1 \mathrm{H}, \mathrm{t}$, $\left.J=8.0 \mathrm{~Hz}, \mathrm{H}-5^{\prime}\right), 6.57(1 \mathrm{H}, \mathrm{dd}, J=16.0 \mathrm{~Hz}, \mathrm{H}-2) ;{ }^{13} \mathrm{C}-$ NMR (125 MHz, MeOD): $\delta 117.0(\mathrm{CH}, \mathrm{C}-2), 118.6(\mathrm{CH}$, C-3'), $120.7\left(\mathrm{CH}, \mathrm{C}-5^{\prime}\right), 122.6\left(\mathrm{C}, \mathrm{C}-1^{\prime}\right), 130.0\left(\mathrm{CH}, \mathrm{C}-6^{\prime}\right)$, $132.5\left(\mathrm{CH}, \mathrm{C}-4^{\prime}\right), 142.5(\mathrm{CH}, \mathrm{C}-3), 158.2\left(\mathrm{C}, \mathrm{C}-2^{\prime}\right), 171.3$ (C, C-1).

trans-cinnamic acid (2): IR (KBr) $v_{\max }\left(\mathrm{cm}^{-1}\right): 3383$, 2951, 2878, 1744, 1632, 1454, 1381, 1304, 1111, 1061, 1022, 941, 829, 663; HRESIMS $\mathrm{m} / z$ 147.0420 $[\mathrm{M}-\mathrm{H}]^{-} ;{ }^{1} \mathrm{H}-\mathrm{NMR}$ (500 MHz, MeOD): $\delta 7.79(1 \mathrm{H}, \mathrm{d}, J=16.0 \mathrm{~Hz}, \mathrm{H}-3), 7.60$ $\left(2 \mathrm{H}, \mathrm{m}, \mathrm{H}-2^{\prime}, 6^{\prime}\right), 7.41\left(3 \mathrm{H}, \mathrm{m}, \mathrm{H}-3^{\prime}, 4^{\prime}, 5^{\prime}\right), 6.49(1 \mathrm{H}$, d, $J=16.0 \mathrm{~Hz}, \mathrm{H}-2) ;{ }^{13} \mathrm{C}-\mathrm{NMR}(125 \mathrm{MHz}, \mathrm{MeOD}): \delta 119.4$ $(\mathrm{CH}, \mathrm{C}-2), 129.2\left(\mathrm{CH}, \mathrm{C}-2^{\prime}\right.$ and $\left.\mathrm{C}-6^{\prime}\right), 130.0\left(\mathrm{CH}, \mathrm{C}-3^{\prime}\right.$ and C-5'), $131.4\left(\mathrm{CH}, \mathrm{C}-4^{\prime}\right), 135.8\left(\mathrm{C}, \mathrm{C}-1^{\prime}\right), 146.4(\mathrm{CH}, \mathrm{C}-3)$, $170.4(\mathrm{C}, \mathrm{C}-1)$. 


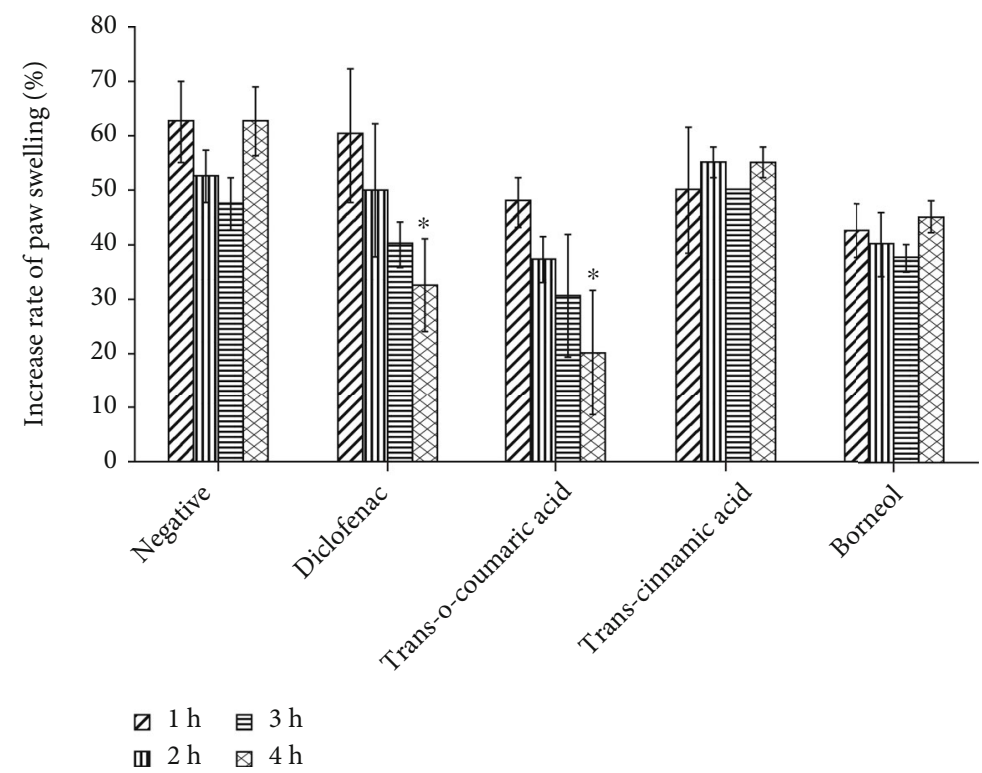

Figure 2: The effect of 1-3 on carrageenan-induced rat paw edema. The mice were peritoneally injected with different compounds, positive or negative control $1 \mathrm{~h}$ before induction of inflammation at the right hind paw using $1 \%$ carrageenan. The swelling of the paw was measured using a plethysmometer before exposure to the compounds and at $1 \mathrm{~h}, 2 \mathrm{~h}, 3 \mathrm{~h}$, and $4 \mathrm{~h}$ after treatment of carrageenan. Data are presented as means $\pm \mathrm{SD}(n=6) .{ }^{*} p<0.05,{ }^{* *} p<0.01$, and ${ }^{* * *} p<0.0001$ as compared with the negative control group.

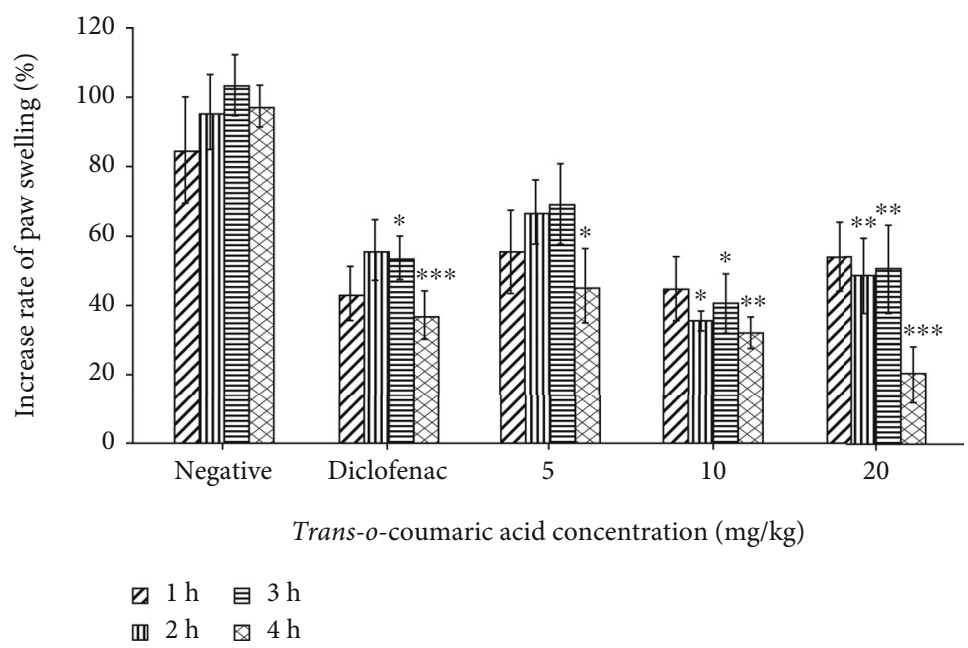

Figure 3: The effect of different concentrations of $\mathbf{1}$ on carrageenan-induced rat paw edema. The mice were peritoneally injected with $\mathbf{1}$ at different concentrations $(20 \mathrm{mg} / \mathrm{kg}, 10 \mathrm{mg} / \mathrm{kg}$, and $5 \mathrm{mg} / \mathrm{kg})$, positive or negative control $1 \mathrm{~h}$ before induction of inflammation at the right hind paw using $1 \%$ carrageenan. The paw edema was measured using a plethysmometer before exposure to the compounds and at $1 \mathrm{~h}$, $2 \mathrm{~h}, 3 \mathrm{~h}$, and $4 \mathrm{~h}$ after treatment of carrageenan. Data are presented as means $\pm \mathrm{SD}(n=6) .{ }^{*} p<0.05,{ }^{* *} p<0.01$, and ${ }^{* * *} p<0.0001$ as compared with the negative control group.

Borneol (3): IR (KBr) $v_{\max }\left(\mathrm{cm}^{-1}\right): 3441,3364,3075$, 2974, 2843, 1667, 1616, 1458, 1427, 1335, 1219, 1092, 991, 910, 868, 752, 698, 590; HRESIMS $\mathrm{m} / z$ 155.1438 $[\mathrm{M}+\mathrm{H}]^{+}$; ${ }^{1} \mathrm{H}-\mathrm{NMR}\left(500 \mathrm{MHz}, \mathrm{CDCl}_{3}\right): \delta 4.01(1 \mathrm{H}, \mathrm{m}, \mathrm{H}-2), 2.27$ (1H, m, H-4), 1.88 (1H, m, H-4), 1.74 (1H, m, H-3a), 1.73 (1H, m, H-6a), $1.52(1 \mathrm{H}, \mathrm{m}, \mathrm{H}-5 \mathrm{a}), 1.27$ (1H, m, H-6b), $1.25(1 \mathrm{H}, \mathrm{m}, \mathrm{H}-5 \mathrm{~b}), 0.87(3 \mathrm{H}, \mathrm{s}, \mathrm{H}-9), 0.86(3 \mathrm{H}, \mathrm{s}, \mathrm{H}-8)$ 0.85 (3H, s, H-10); ${ }^{13} \mathrm{C}-\mathrm{NMR}\left(125 \mathrm{MHz}, \mathrm{CDCl}_{3}\right): \delta 13.3$ $\left(\mathrm{CH}_{3}, \mathrm{C}-10\right), 18.7\left(\mathrm{CH}_{3}, \mathrm{C}-8\right), 20.2\left(\mathrm{CH}_{3}, \mathrm{C}-9\right), 25.9\left(\mathrm{CH}_{2}\right.$,
C-6), $28.3\left(\mathrm{CH}_{2}, \mathrm{C}-5\right), 39.0\left(\mathrm{CH}_{2}, \mathrm{C}-3\right), 45.1(\mathrm{CH}, \mathrm{C}-4)$, 48.0 (C, C-7), 49.5 (C, C-1), 77.3 (CH, C-2).

3.2. Anti-Inflammatory Assay. To determine the antiinflammatory activity, an in vivo experiment examined acute carrageenan-induced inflammation in mice. Particularly, mice were injected intraperitoneally with 1-3 or positive or negative controls $1 \mathrm{~h}$ before inducing inflammation at the right hind paw with $1 \%$ carrageenan. The intensity of edema 
development was measured via plethysmometry. Of the three, 1 significantly reduced edema at a dose of $20 \mathrm{mg} / \mathrm{kg}$, similar to that of the positive control (Figure 2). Four hours after the carrageenan treatment, the paw volume of group 1 mice was reduced by $68 \%(p<0.05)$ compared to $48 \%$ $(p<0.05)$ for the positive control. The swelling in the negative control group was almost unchanged $4 \mathrm{~h}$ after the carrageenan treatment. Similar results were attained in groups 2 and 3 with slight edema suppression, approximately $12 \%$ and $28 \%$, respectively $(p>0.05)$. Therefore, 1 was chosen for further study.

The anti-inflammatory bioactivity of $\mathbf{1}$ at different concentrations was confirmed using a similar method. The mice were injected intraperitoneally with 5,10 , or $20 \mathrm{mg} / \mathrm{kg}$ of $\mathbf{1}$ $1 \mathrm{~h}$ before carrageenan was injected to induce inflammation. As displayed in Figure 3, 1 significantly ameliorated the inflammation in a dose-dependent manner. At $5 \mathrm{mg} / \mathrm{kg}, 1$ significantly reduced the edema $4 \mathrm{~h}$ after carrageenan treatment $(p<0.05)$. At $10 \mathrm{mg} / \mathrm{kg}$ and 20/kg, 1 effectively moderated the paw edema intensity to approximately $67 \%$ and $79 \%$, respectively, $(p<0.0001), 4 \mathrm{~h}$ after carrageenan treatment compared to $62 \%$ for the positive control $(p<0.0001)$. There was no significant difference in the paw volume reduction between dosages of $10 \mathrm{mg} / \mathrm{kg}$ and $20 \mathrm{mg} / \mathrm{kg}$.

The photographs of inflamed mouse paws in groups 1, the negative control, and the positive control are shown in Figure 4 . The reduction in the paw volumes of the mice in group 1 and the positive controls was obvious.

3.3. Antimicrobial Assay. To evaluate the antimicrobial ability of 1-3, different concentrations of 1-3 were added to Gram-positive ( $S$. aureus, B subtilis) and Gram-negative ( $P$. aeruginosa, E. coli) bacterial cultures. After incubation, the MIC was determined and the result is shown (Table 1). Both $\mathbf{1}$ and $\mathbf{2}$ comparably inhibited the growth of Gram-positive strains without affecting Gram-negative strains. No obvious bacterial inhibition was observed for $\mathbf{3}$ against either Grampositive or Gram-negative strains.

3.4. Docking Studies. The RMSD of the native ligands when redocked to COX-1 and COX-2 were 0.56 and $0.45 \AA$, respectively. These values showed a good binding mode which was reliable for relative free binding energy MMGBSA postcalculations.

In COX-1 protein, the reference diclofenac had the lowest free energy at $-29.3 \mathrm{kcal} / \mathrm{mol}$, and $\mathbf{1}$ and $\mathbf{2}$ had higher values at -8.2 , and $-8.8 \mathrm{kcal} / \mathrm{mol}$, respectively, while 3 was screened out of both COX-1 and COX-2 proteins due to large steric effect structure (Table 2, Supporting S23). In COX-2 protein, diclofenac maintained its best inhibitor activity at $33.9 \mathrm{kcal} / \mathrm{mol}$ and molecule 1 showed competitiveness with diclofenac at $-29.7 \mathrm{kcal} / \mathrm{mol}$. These estimates were well consistent with in vivo results where $\mathbf{1}$ ameliorated significantly the inflammation similar to diclofenac. Molecule 2 exhibited a poorer inhibitory capacity at $-25.2 \mathrm{kcal} / \mathrm{mol}$. In XP docking results, ligand 1 was held tightly by three h-bond donors from the Arg 120, Tyr 355, and Ser 530 residues whereas ligand 2 possessed only two h-bonds donors with Arg 120 and Tyr 355 (Table 2, Figure 5). Taken together, 1 showed

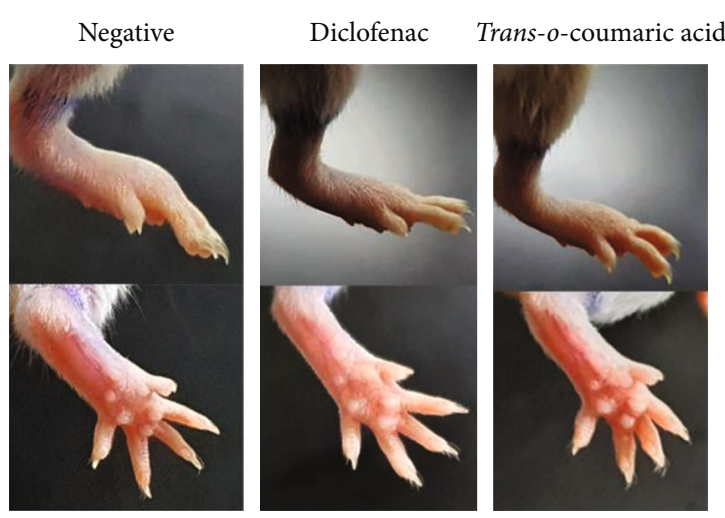

FIgURE 4: The images of the carrageenan-treated paw after injection of diclofenac or trans-o-coumaric acid. The mice were peritoneally injected with saline (negative), diclofenac (positive), or trans-ocoumaric acid, followed by inflammation induction at the right hind paw using $1 \%$ carrageenan. At $4 \mathrm{~h}$ after treatment with carrageenan, the treated paws were pictured to compare the size.

TABLE 1: The MICs of 1-3 on different bacterial strains.

\begin{tabular}{lcccc}
\hline \multirow{2}{*}{ Bacterial strains } & \multicolumn{4}{c}{ MICs of compounds (mM) } \\
& Ciprofloxacin & $\mathbf{1}$ & $\mathbf{2}$ & $\mathbf{3}$ \\
\hline Staphylococcus aureus & $0.648 \times 10^{-3}$ & 1.52 & 1.69 & 6.49 \\
Bacillus subtilis & $0.648 \times 10^{-3}$ & 3.04 & 3.37 & 6.49 \\
Pseudomonas aeruginosa & $0.041 \times 10^{-3}$ & 6.10 & 6.75 & 6.49 \\
Escherichia coli & $0.041 \times 10^{-3}$ & 6.1 & 6.75 & 6.49 \\
\hline
\end{tabular}

a competitive inhibition with diclofenac in COX-2 and has the relative free binding energy similar to diclofenac.

3.5. Molecular Dynamics Simulations Predict the Inhibition Mechanism by Molecule 1. Simulation time 50 ns with RMSD protein and ligand RMSD in the range 1-3 A showed that the system had equilibrium. From the early stages of the simulation process, the h-bond between ligand $\mathbf{1}$ and Ser 530 in docking pose was not stable, whereby the Arg 120, Tyr 355, and Arg 513 were the main contact residues over the course of the trajectory. Arg 120 stands out with a percentage of hbond interactions greater than 1.2, followed by Tyr 355 at 1.1 and Arg 513 at 0.7. The contribution of water bridges was minor for Arg 120 and Tyr 355 but 0.5 for Arg 513 Figures 6(a), B and 6(b). On the other hand, quantifying the RMSF showed that most atoms ligand $\mathbf{1}$ fluctuated in the range of 1.5 when fitted with COX-2 protein. This finding demonstrated the thermodynamic stability of the ligandprotein system (Figure 6(c)). In general, the in silico research exhibited the COX-2 inhibitor capacity of compound 1 by generating h-bonds at the positions of Arg 120, Tyr 355, and Arg 513 residues.

\section{Discussion}

Compounds 1-3 were isolated from $n$-hexane extract of $D$. benenica Q.B.Nguyen \& Škorničk rhizome. The antiinflammatory and antimicrobial bioactivities of 1-3 were 
TABLE 2: The XP docking scores and MM-GBSA binding free energy estimations ( $\mathrm{kcal} / \mathrm{mol})$ of three molecules $\mathbf{1}, \mathbf{2}$, and diclofenac reference drug.

\begin{tabular}{|c|c|c|c|c|c|c|c|c|}
\hline \multirow[b]{2}{*}{ Compounds } & \multicolumn{4}{|c|}{ COX-1 } & \multicolumn{4}{|c|}{ COX -2} \\
\hline & $\begin{array}{l}\text { XP GlideScore } \\
\text { (kcal/Mol) }\end{array}$ & $\begin{array}{c}\text { MM-GBSA } \\
(\mathrm{kcal} / \mathrm{Mol})\end{array}$ & $\begin{array}{c}\text { No of } \\
\text { h-bonds }\end{array}$ & Residues & $\begin{array}{l}\text { XP GlideScore } \\
\text { (kcal/Mol) }\end{array}$ & $\begin{array}{c}\text { MM-GBSA } \\
(\mathrm{kcal} / \mathrm{Mol})\end{array}$ & $\begin{array}{c}\text { No of } \\
\text { h-bonds }\end{array}$ & Residues \\
\hline 1 & -5.7 & -8.2 & 2 & $\begin{array}{l}\text { Ser516, } \\
\text { Phe518 }\end{array}$ & -6.5 & -29.7 & 3 & $\begin{array}{l}\text { Arg120, Tyr355, } \\
\text { Ser530 }\end{array}$ \\
\hline 2 & -5.1 & -8.8 & 2 & $\begin{array}{l}\text { Ser516, } \\
\text { Phe518 }\end{array}$ & -5.3 & -25.2 & 2 & Arg120, Tyr355 \\
\hline Diclofenac & -7.5 & -29.3 & - & - & -8.5 & -33.9 & 1 & Ser 530 \\
\hline
\end{tabular}

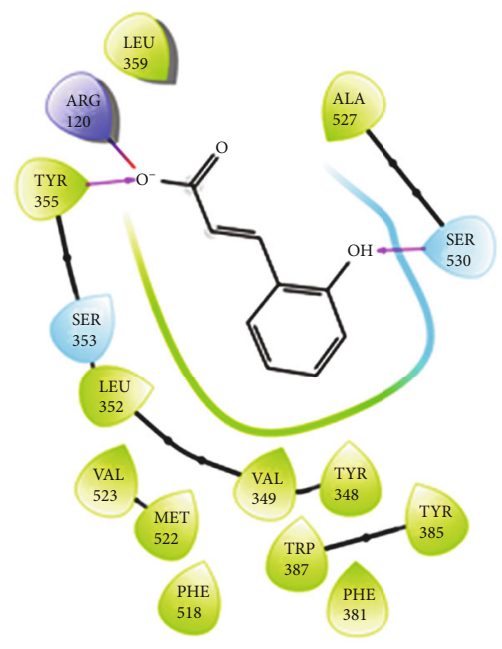

1

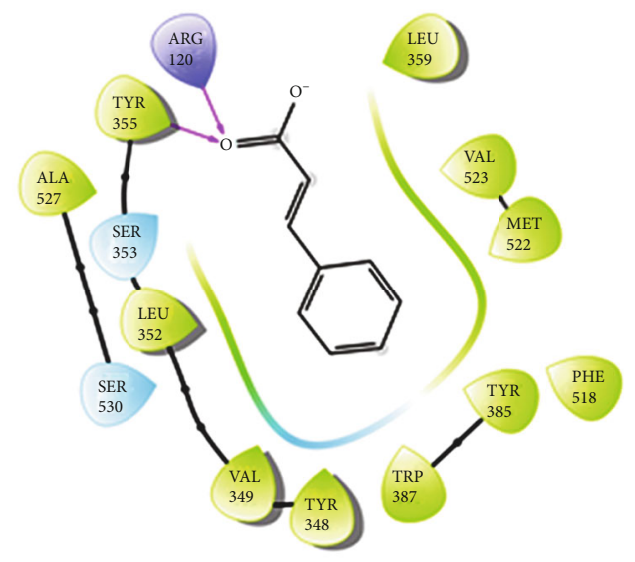

2

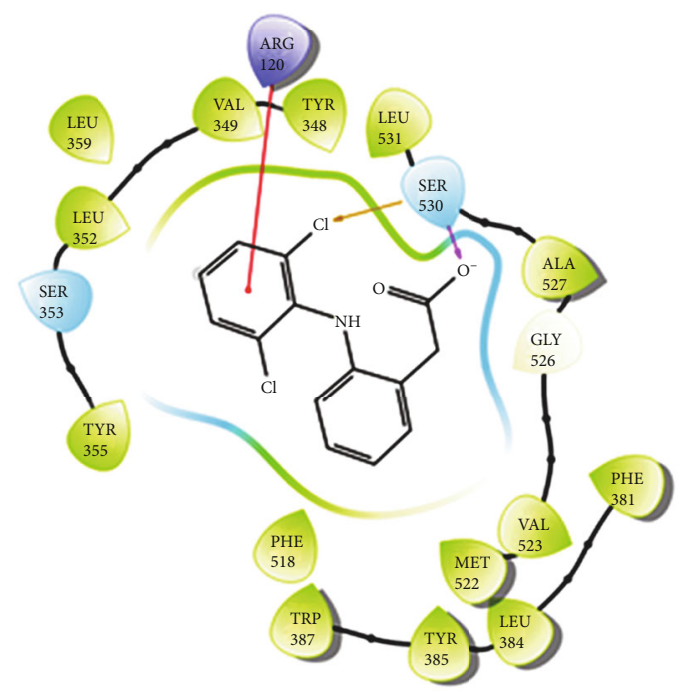

Diclofenac

\begin{tabular}{|c|c|c|c|c|}
\hline Charged (negative) & Polar & Distance & $\rightarrow$ & Pi-cation \\
\hline Charged (positive) & Unspecified residue & H-bond & - & Salt bridge \\
\hline Glycine & Water & Halogen bond & 0 & Solvent exposure \\
\hline Hydrophobic & Hydration site & Metal coordination & & \\
\hline Metal & Hydration site (displaced) & Pi-Pi stacking & & \\
\hline
\end{tabular}

FIGURE 5: Binding poses of three molecules 1, 2, and the diclofenac with COX-2 proteins. The additional information in 2D diagrams was present. 


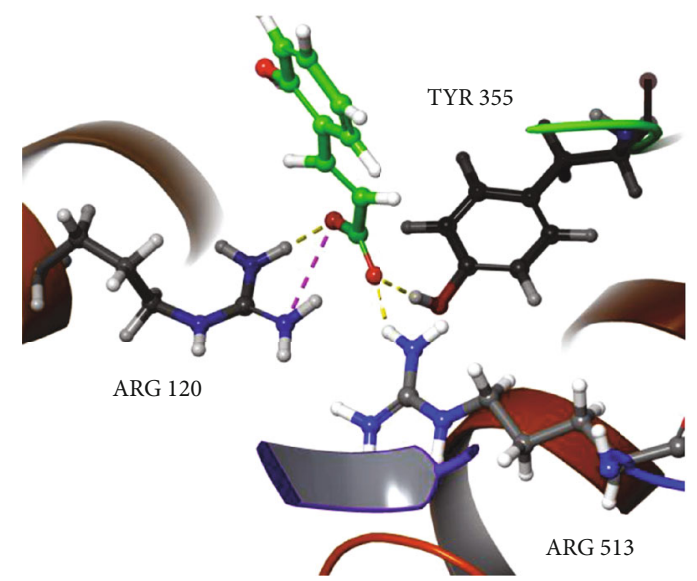

(A)

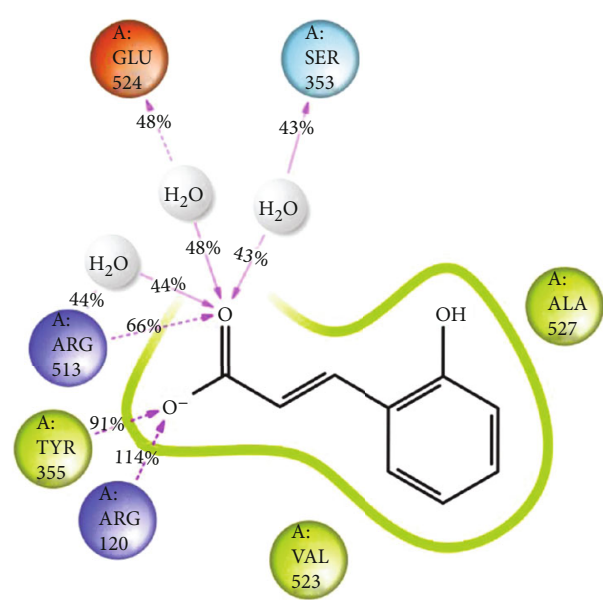

(B)

(a)

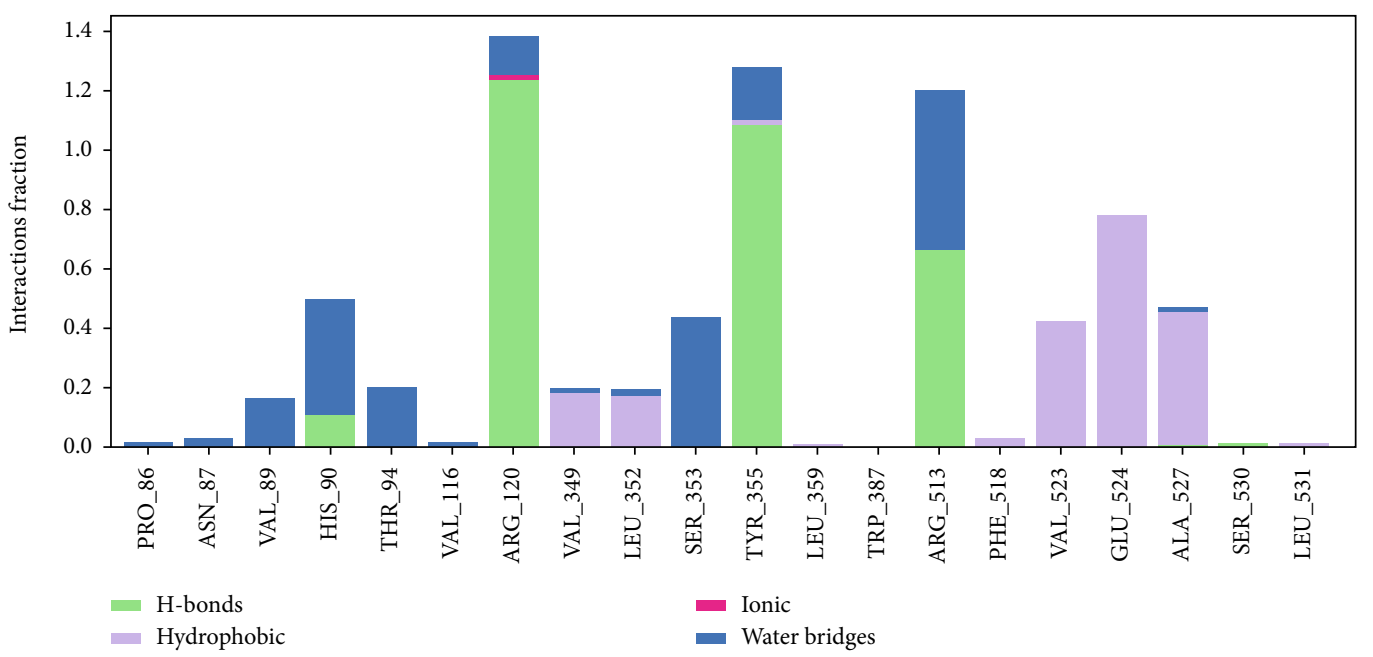

(b)

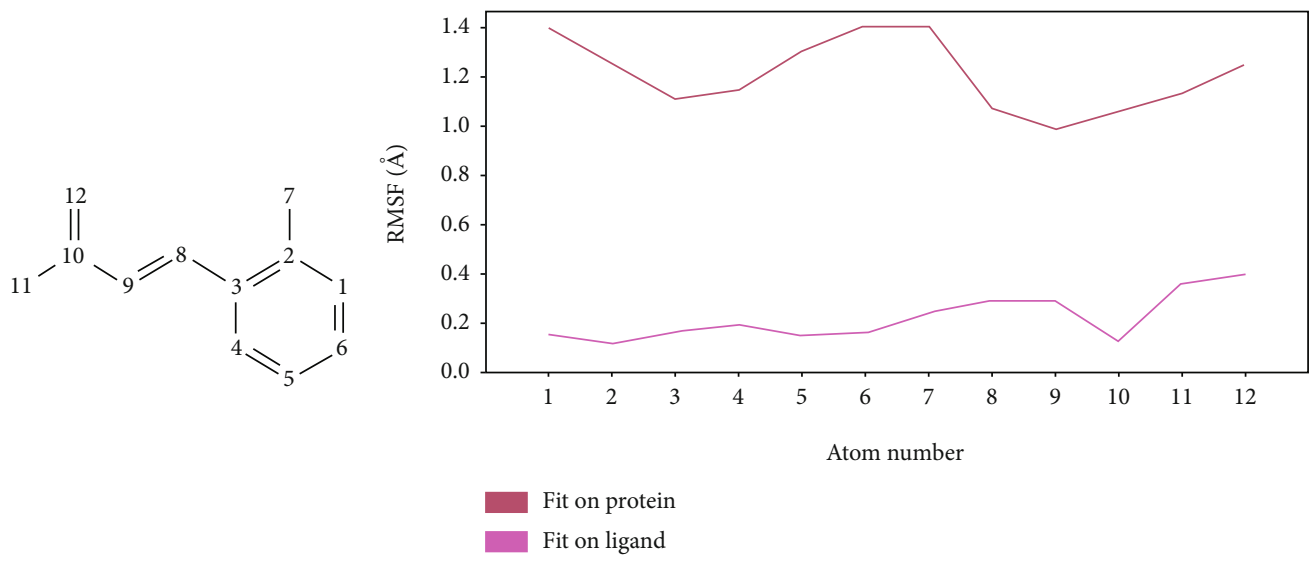

(A)

(c)

Figure 6: Molecular dynamics simulations of molecule 1 in COX-2 binding site. (a) Snapshots 3D (A) from stable segments of molecular dynamics simulations show that 1 bound to Arg120, Tyr 355, and Arg 513 by three h-bonds and one salt bridge. (B) The interactions occur more than $30.0 \%$ of the simulation time in the selected trajectory $(0.00$ through $50.05 \mathrm{nsec})$. (b) The interaction diagram demonstrates the percentage interaction of ligand $\mathbf{1}$ with surrounding residues. (c) Root mean-squared fluctuation (RMSF) of molecule $\mathbf{1}$ fitted on the protein (red) or ligand (purple line). The atom numbers of $\mathbf{1}$ (A) correspond to the RMSF plot $x$-axis (B). The ligand is shown in green ball-and-stick, oxygen atoms in red, carbon atoms in black, and nitrogen atoms in blue. 
evaluated in vivo and in vitro, respectively, revealing that 1 inhibited inflammation, while $\mathbf{1}$ and $\mathbf{2}$ had antimicrobial activity against Gram-positive bacteria.

Since inflammation is involved in diseases, the finding of compounds that inhibit inflammation is of interest. Many methods have been applied to determine the antiinflammation activity. Carrageenan-induced paw edema is one of the in vivo models which has been used to evaluate anti-inflammatory activities and has long been established as a valid model to study new anti-inflammatory drugs. Carrageenan causes acute inflammation by inhibiting monocyte migration and preventing prostaglandin release $[40,41]$. Diclofenac is a commonly nonsteroidal anti-inflammatory drug (NSAID) that is effective for treating acute, chronic pain and inflammatory conditions. Similar to other NSAIDs, diclofenac inhibits prostaglandin release by targeting cyclooxygenase-1 and cyclooxygenase-2 (COX-1 and COX-2) [42]. Here, 1 significantly alleviated the edema caused by carrageenan in mice comparably to diclofenac (Figures 3 and 4). Our result is consistent with the anti-inflammatory effect of $p$-coumaric acid, as $p$-coumaric acid isolated from Oldenlandia diffusa also ameliorated inflammation symptoms [23]. In arthritic rats, $p$-coumaric acid prevented the expression of tumor necrosis factor $(\mathrm{TNF}-\alpha)$ in synovial tissues and circulating immune complexes [43]. In lipopolysaccharide- (LPS-) stimulated RAW264.7, p-coumaric acid significantly inhibited the expression of inducible nitric oxide synthase, COX- 2 , interleukin- $1 \beta$, and TNF- $\alpha$. Here, for the first time, we demonstrated the antiinflammatory properties of trans-o-coumaric acid (Figures 2 and 3). Liao et al. found that trans-cinnamic did not have anti-inflammatory activity [44]. In our study, trans-cinnamic acid exhibited low anti-inflammatory activity (Figure 2). However, our result for 3 differed from that reported for borneol, which significantly decreased the expression of inflammatory factors, including nitric oxide, TNF- $\alpha$, and interleukin- 6 in LPS-induced RAW 264.7 macrophages in vitro [29]. In another study, mice treated with $\geq 50 \mathrm{mg} / \mathrm{kg}$ borneol showed significantly reduced migration of carrageenan-induced leukocytes to the peritoneal cavity [30]. In our study, $20 \mathrm{mg} / \mathrm{kg}$ borneol slightly ameliorated the swelling compared to the negative control, by approximately $38 \%$ after $4 \mathrm{~h}$ of carrageenan treatment (Figure 3).

One study revealed information on the growth inhibition of trans-o-coumaric acid against B. subtilis, Proteus vulgaris, and $S$. aureus [26], whereas another study showed the antiproliferation activity of $p$-coumaric acid against Grampositive (Streptococcus pneumoniae, S. aureus, and B. subtilis) and Gram-negative (E. coli, Shigella dysenteriae, and Salmonella typhimurium) bacteria with MICs of $10-80 \mu \mathrm{g} / \mathrm{mL}$ [45]. Taofiq et al. demonstrated the antimicrobial effects of p-coumaric acid against Gram-positive (methicillin-resistant and methicillin-sensitive $S$. aureus and Enterococcus faecalis) and Gram-negative (E. coli and Proteus mirabilis) with MICs of $0.5-1$ and $2.5 \mathrm{mg} / \mathrm{mL}$, respectively [20]. Similarly, a nanoemulsion of trans-cinnamic acid reduced the growth of $S$. aureus, S. typhimurium, and $P$. aeruginosa with MICs of $0.78,1.56$, and $3.13 \mathrm{mg} / \mathrm{mL}$, respectively [46]. Trans-cinnamic acid prevented the proliferation of Gram-positive strains (B. subtilis, Bacillus thuringiensis, and Lysinibacillus xylanilyticus) with a MIC of $1 \mathrm{mg} / \mathrm{mL}$ and Gram-negative strains (E. coli, Klebsiella pneumoniae) with a MIC of $>1 \mathrm{mg} / \mathrm{mL}$. Trans-cinnamic acid was more effective against Aeromonas sobria (MIC $=0.25 \mathrm{mg} / \mathrm{mL}$ ) [47]. Cinnamic acid displayed comparable activity against Gram-positive (methicillin-resistant and methicillin-sensitive S. aureus and E. faecalis) and Gram-negative (E. coli and Proteus mirabilis) strains with a MIC of $\sim 1 \mathrm{mg} / \mathrm{mL}$ [20]. Borneol had antimicrobial effects against Gram-positive bacteria such as $S$. aureus and E. faecalis (MIC $=2-4 \mu \mathrm{L} / \mathrm{mL}$ ) [27]. In another study, however, borneol lacked antimicrobial activity [48]. In our study, $\mathbf{1}$ and $\mathbf{2}$ reduced the proliferation of Grampositive strains $(\mathrm{MICs}=1.52-3.37 \mathrm{mM})$ more effectively than $3(\mathrm{MIC}=6.49 \mathrm{mM})$ (Table 1$)$. 1-3 had low antimicrobial activity against Gram-negative bacterial strains (E. coli and $P$. aeruginosa) $(\mathrm{MICs}=6.1-6.75 \mathrm{mM})$.

\section{Conclusions}

We isolated 1-3 from an $n$-hexane extract of $D$. benenica Q.B.Nguyen \& Škorničk rhizomes and evaluated their anti-inflammatory and antimicrobial bioactivities. In a carrageenan-induced paw edema assay, 1 inhibited the intensity of edema comparably to diclofenac. The in silico research exhibited that the anti-inflammation activity of $\mathbf{1}$ may be mediated by inhibiting COX-2 via generating h-bonds at the positions of Arg 120, Tyr 355, and Arg 513 residues. Furthermore, in an antimicrobial assay, $\mathbf{1}$ and $\mathbf{2}$ hampered the growth of Gram-positive (S. aureus and B. subtilis) but had low activity against Gram-negative strains. Taken together, our results revealed that $\mathbf{1}$ isolated from $D$. benenica might have the anti-inflammatory function whereas $\mathbf{1}$ and $\mathbf{2}$ could reduce the growth of several Gram-positive bacteria.

\section{Data Availability}

The data used to support the findings of this study are available from the corresponding author upon request.

\section{Conflicts of Interest}

The authors declare that there is no conflict of interest regarding the publication of this paper.

\section{Acknowledgments}

The authors would like to thank Dr. Duc Duy Vo of Uppsala University, Sweden, and all members of the HighPerformance Computing (HPC) group of Ton Duc Thang University, Vietnam, who have been sincerely recognized for their contributions to this study.

\section{Supplementary Materials}

Figure S1: FT-IR spectrum $(\mathrm{KBr})$ of compound (1). Figure S2: ${ }^{1} \mathrm{H}-\mathrm{NMR}$ spectrum (MeOD, $\left.500 \mathrm{MHz}\right)$ of compound (1). Figure S3: ${ }^{1} \mathrm{H}-\mathrm{NMR}$ spectrum (MeOD, $\left.500 \mathrm{MHz}\right)$ of compound (1) (expansion 1). Figure S4: ${ }^{13} \mathrm{C}-\mathrm{NMR}$ spectrum (MeOD, $125 \mathrm{MHz}$ ) compound (1). Figure S5: ${ }^{13} \mathrm{C}-\mathrm{NMR}$ spectrum (MeOD, $125 \mathrm{MHz}$ ) compound (1) (expansion 1). 
Figure S6: DEPT spectrum (MeOD, $125 \mathrm{MHz}$ ) compound (1) (expansion 1). Figure S7: HRESIMS spectrum of compound (1). Figure S8: FT-IR spectrum (KBr) of compound (2). Figure S9: ${ }^{1} \mathrm{H}-\mathrm{NMR}$ spectrum $(\mathrm{MeOD}, 500 \mathrm{MHz})$ of compound (2). Figure S10: ${ }^{1} \mathrm{H}-\mathrm{NMR}$ spectrum (MeOD, $500 \mathrm{MHz}$ ) of compound (2) (expansion 1). Figure S11: ${ }^{13} \mathrm{C}$ NMR spectrum (MeOD, $125 \mathrm{MHz}$ ) compound (2). Figure S12: ${ }^{13} \mathrm{C}-\mathrm{NMR}$ spectrum (MeOD, $125 \mathrm{MHz}$ ) compound (2) (expansion 1). Figure S13:. DEPT spectrum (MeOD, $125 \mathrm{MHz}$ ) compound (2). Figure S14: HRESIMS spectrum of compound (3). Figure S15: FT-IR spectrum (KBr) of compound (3). Figure S16: ${ }^{1} \mathrm{H}-\mathrm{NMR}$ spectrum $\left(\mathrm{CDCl}_{3}\right.$, $500 \mathrm{MHz}$ ) of compound (3). Figure S17: ${ }^{1} \mathrm{H}-\mathrm{NMR}$ spectrum $\left(\mathrm{CDCl}_{3}, 500 \mathrm{MHz}\right)$ of compound (3) (expansion 1). Figure S18: ${ }^{1} \mathrm{H}-\mathrm{NMR}$ spectrum $\left(\mathrm{CDCl}_{3}, 500 \mathrm{MHz}\right)$ of compound (3) (expansion 2). Figure S19: ${ }^{13} \mathrm{C}-\mathrm{NMR}$ spectrum $\left(\mathrm{CDCl}_{3}\right.$, $125 \mathrm{MHz}$ ) compound (3). Figure S20: ${ }^{13} \mathrm{C}-\mathrm{NMR}$ spectrum $\left(\mathrm{CDCl}_{3}, 125 \mathrm{MHz}\right.$ ) compound (3) (expansion 1). Figure S21: DEPT spectrum $\left(\mathrm{CDCl}_{3}, 125 \mathrm{MHz}\right)$ compound (3). Figure S22: HRESIMS spectrum of compound (3). Figure S23: Binding poses of three molecule 1, 2 and the diclofenac with COX-1 proteins. (Supplementary Materials)

\section{References}

[1] K. Newton and V. M. Dixit, "Signaling in innate immunity and inflammation," Cold Spring Harbor perspectives in biology, vol. 4, no. 3, article a006049, 2012.

[2] L. Chen, H. Deng, H. Cui et al., "Inflammatory responses and inflammation-associated diseases in organs," Oncotarget, vol. 9, no. 6, pp. 7204-7218, 2018.

[3] R. Pahwa, A. Goyal, P. Bansal, and I. Jialal, Chronic Inflammation, StatPearls Publishing, Treasure Island (FL), 2020.

[4] D. Furman, J. Campisi, E. Verdin et al., "Chronic inflammation in the etiology of disease across the life span," Nature, vol. 25, pp. 1822-1832, 2019.

[5] H. P. Kim, H. Lim, and Y. S. Kwon, “Therapeutic potential of medicinal plants and their constituents on lung inflammatory disorders," Biomolecules \& Therapeutics, vol. 25, no. 2, pp. 91104, 2017.

[6] O. O. Oguntibeju, "Medicinal plants with anti-inflammatory activities from selected countries and regions of Africa," Journal of Inflammation Research, vol. 11, pp. 307-317, 2018.

[7] M. Ghasemian, S. Owlia, and M. B. Owlia, "Review of antiinflammatory herbal medicines," Advances in Pharmacological Sciences, vol. 2016, Article ID 9130979, 11 pages, 2016.

[8] M. M. Cowan, "Plant products as antimicrobial agents," Clinical Microbiology Reviews, vol. 12, no. 4, pp. 564-582, 1999.

[9] S. Mickymaray, "Efficacy and mechanism of traditional medicinal plants and bioactive compounds against clinically important pathogens," Antibiotics, vol. 8, no. 4, p. 257, 2019.

[10] T. Rehse and W. J. Kress, "Distichochlamys rubrostriata (Zingiberaceae), a new species from northern Vietnam," Brittonia, vol. 55, no. 3, pp. 205-208, 2003.

[11] N. S. Mashhadi, R. Ghiasvand, G. Askari, M. Hariri, L. Darvishi, and M. R. Mofid, "Anti-oxidative and antiinflammatory effects of ginger in health and physical activity: review of current evidence," International Journal of Preventive Medicine, vol. 4, pp. S36-S42, 2013.
[12] K. Norajit, N. Laohakunjit, and O. Kerdchoechuen, "Antibacterial effect of five Zingiberaceae essential oils," Molecules, vol. 12, no. 8, pp. 2047-2060, 2007.

[13] I. N. Chen, C. C. Chang, C. C. Ng, C. Y. Wang, Y. T. Shyu, and T. L. Chang, "Antioxidant and antimicrobial activity of Zingiberaceae plants in Taiwan," Plant Foods for Human Nutrition, vol. 63, no. 1, pp. 15-20, 2008.

[14] M. Habsah, M. Amran, M. M. Mackeen et al., "Screening of Zingiberaceae extracts for antimicrobial and antioxidant activities," Journal of Ethnopharmacology, vol. 72, no. 3, pp. 403-410, 2000.

[15] T. U. T. Ngo, T. D. Tran, T. V. Pham, and D. V. Ho, "The chemical constituents of Quang Nam Distichochlamys benenica Q.B.Nguyen \& Škorničk. Plants from Vietnam," Vietnam Journal of Chemistry, vol. 55, pp. 81-85, 2017.

[16] T. V. Pham, V. Truong, N. T. T. Dang, H. Q. Vo, and D. V. Ho, "Chemical composition of the essential oils of Distichochlamys citrea leaves collected from central Vietnam," Vietnam journal of Chemistry, vol. 55, no. 4E23, pp. 358-362, 2017.

[17] T. V. Pham, H. T. Nguyen, K. V. Nguyen, and D. V. Ho, "Chemical composition of the essential oils of Distichochlamys citrea from ALuoi-Thua Thien Hue," Journal of Medicine and Pharmacy, Hue University of Medicine and Pharmacy, vol. 25, pp. 43-48, 2014.

[18] H. T. N. Hoang, T. T. T. Dinh, T. V. Pham, H. B. T. Le, and D. V. Ho, "Chemical composition and acetylcholinesterase inhibitory activity of esssential oil from the rhizomes of Distichochlamys benenica," Hue University Journal of Science: Natural Science, vol. 129, no. 1D, pp. 43-49, 2020.

[19] S. Adisakwattana, "Cinnamic acid and its derivatives: mechanisms for prevention and management of diabetes and its complications," Nutrients, vol. 9, no. 2, p. 163, 2017.

[20] O. Taofiq, S. A. Heleno, R. C. Calhelha et al., "Phenolic acids, cinnamic acid, and ergosterol as cosmeceutical ingredients: stabilization by microencapsulation to ensure sustained bioactivity," Microchemical Journal, vol. 147, pp. 469-477, 2019.

[21] E. Pontiki, D. Hadjipavlou-Litina, K. Litinas, and G. Geromichalos, "Novel cinnamic acid derivatives as antioxidant and anticancer agents: design, synthesis and modeling studies," Molecules, vol. 9, no. 7, pp. 9655-9674, 2014.

[22] M. Nardini and I. Garaguso, "Characterization of bioactive compounds and antioxidant activity of fruit beers," Food Chemistry, vol. 305, article 125437, 2019.

[23] H. Zhu, Q. H. Liang, X. G. Xiong et al., "Anti-inflammatory effects of $p$-coumaric acid, a natural compound of Oldenlandia diffusa, on arthritis model rats," Evidence-based Complementary and Alternative Medicine, vol. 2018, Article ID 5198594, 9 pages, 2018.

[24] H. Boz, " $p$-Coumaric acid in cereals: presence, antioxidant and antimicrobial effects," International Journal of Food Science and Technology, vol. 50, no. 11, pp. 2323-2328, 2015.

[25] K. Pei, J. Ou, J. Huang, and S. Ou, " $p$-Coumaric acid and its conjugates: dietary sources, pharmacokinetic properties and biological activities," Journal of the Science of Food and Agriculture, vol. 96, no. 9, pp. 2952-2962, 2016.

[26] M. Kowczyk-Sadowy, R. Świsłocka, H. Lewandowska, J. Piekut, and W. Lewandowski, "Spectroscopic (FT-IR, FTRaman, ${ }^{1} \mathrm{H}$ - and $\left.{ }^{13} \mathrm{C}-\mathrm{NMR}\right)$, theoretical and microbiological study of trans $o$-coumaric acid and alkali metal $o$-coumarates," Molecules, vol. 20, no. 2, pp. 3146-3169, 2015.

[27] A. M. Ojeda-Sana, C. M. van Baren, M. A. Elechosa, M. A. Juárez, and S. Moreno, "New insights into antibacterial and 
antioxidant activities of rosemary essential oils and their main components," Food Control, vol. 31, no. 1, pp. 189-195, 2013.

[28] Q. L. Zhang, B. M. Fu, and Z. J. Zhang, "Borneol, a novel agent that improves central nervous system drug delivery by enhancing blood-brain barrier permeability," Drug Delivery, vol. 24, no. 1, pp. 1037-1044, 2017.

[29] L. Zou, Y. Zhang, W. Li et al., "Comparison of chemical profiles, anti-inflammatory activity, and UPLC-Q-TOF/MS-based metabolomics in endotoxic fever rats between synthetic borneol and natural borneol," Molecules, vol. 22, no. 9, article 1446, 2017.

[30] J. R. Almeida, G. R. Souza, J. C. Silva et al., "Borneol, a bicyclic monoterpene alcohol, reduces nociceptive behavior and inflammatory response in mice," The Scientific World Journal, vol. 2013, Article ID 808460, 5 pages, 2013.

[31] R. Liu, A. Li, and A. Sun, "Preparative isolation and purification of hydroxyanthraquinones and cinnamic acid from the chinese medicinal herb Rheum officinale Baill. by high-speed counter-current chromatography," Journal of Chromatography A, vol. 1052, no. 1-2, pp. 217-221, 2004.

[32] Y. H. Wang, H. Y. Tian, A. M. Wang, H. X. Wang, and C. L. Zou, "A green and solvent-free process for preparation of high- purity (-)-borneol from leaves of Blumea balsamifera (L) DC," Tropical Journal of Pharmaceutical Research, vol. 13, no. 1, pp. 41-46, 2014.

[33] C. A. Winter, E. A. Risley, and G. W. Nuss, "Carrageenininduced edema in hind paw of the rat as an assay for antiinflammatory drugs," Proceedings of the Society for Experimental Biology and Medicine, vol. 111, no. 3, pp. 544-547, 1962.

[34] M. Safari and S. Ahmady-Asbchin, "Evaluation of antioxidant and antibacterial activities of methanolic extract of medlar (Mespilus germanicaL.) leaves," Biotechnology \& Biotechnological Equipment, vol. 33, no. 1, pp. 372-378, 2019.

[35] J. Li, R. Abel, K. Zhu, Y. Cao, S. Zhao, and R. A. Friesner, “The VSGB 2.0 model: a next generation energy model for high resolution protein structure modeling," Proteins, vol. 79, no. 10, pp. 2794-2812, 2011.

[36] G. M. Sastry, M. Adzhigirey, T. Day, R. Annabhimoju, and W. Sherman, "Protein and ligand preparation: parameters, protocols, and influence on virtual screening enrichments," Journal of Computer-Aided Molecular Design, vol. 27, no. 3, pp. 221-234, 2013.

[37] R. A. Friesner, R. B. Murphy, M. P. Repasky et al., "Extra precision glide: docking and scoring incorporating a model of hydrophobic enclosure for protein-ligand complexes," Journal of Medicinal Chemistry, vol. 49, no. 21, pp. 6177-6196, 2006.

[38] P. A. Greenidge, C. Kramer, J. C. Mozziconacci, and R. M. Wolf, "MM/GBSA binding energy prediction on the PDBbind data set: successes, failures, and directions for further improvement," Journal of Chemical Information and Modeling, vol. 53, no. 1, pp. 201-209, 2013.

[39] K. J. Bowers, D. E. Chow, H. Xu et al., "Scalable algorithms for molecular dynamics simulations on commodity clusters," in ACM/IEEE SC 2006 Conference (SC'06), pp. 43-43, Tampa, FL, USA, 2006.

[40] D. A. Willoughby and M. DiRosa, "Studies on the mode of action of non-steroid anti-inflammatory drugs," Annals of the Rheumatic Diseases, vol. 31, no. 6, p. 540, 1972.

[41] C. J. Morris, "Carrageenan-induced paw edema in the rat and mouse," Methods in Molecular Biology, vol. 225, pp. 115-121, 2003.
[42] T. J. Gan, "Diclofenac: an update on its mechanism of action and safety profile," Current Medical Research and Opinion, vol. 26, no. 7, pp. 1715-1731, 2010.

[43] S. J. Pragasam, V. Venkatesan, and M. Rasool, "Immunomodulatory and anti-inflammatory effect of $p$-coumaric acid, a common dietary polyphenol on experimental inflammation in rats," Inflammation, vol. 36, no. 1, pp. 169-176, 2013.

[44] J. C. Liao, J. S. Deng, C. S. Chiu et al., "Anti-inflammatory activities of Cinnamomum cassia constituents in vitro and in vivo," Evidence-based Complementary and Alternative Medicine, vol. 2012, Article ID 429320, 12 pages, 2012.

[45] Z. Lou, H. Wang, S. Rao, J. Sun, C. Ma, and J. Li, "p-Coumaric acid kills bacteria through dual damage mechanisms," Food Control, vol. 25, no. 2, pp. 550-554, 2012.

[46] K. S. Letsididi, Z. Lou, R. Letsididi, K. Mohammed, and B. L. Maguy, "Antimicrobial and antibiofilm effects of trans -cinnamic acid nanoemulsion and its potential application on lettuce," LWT, vol. 94, pp. 25-32, 2018.

[47] S. Yilmaz, M. Sova, and S. Ergün, "Antimicrobial activity of trans-cinnamic acid and commonly used antibiotics against important fish pathogens and nonpathogenic isolates," Journal of Applied Microbiology, vol. 125, no. 6, pp. 1714-1727, 2018.

[48] R. Kotan, S. Kordali, and A. Cakir, "Screening of antibacterial activities of twenty-one oxygenated monoterpenes," Zeitschrift fur Naturforschung. C, Journal of biosciences (Z Naturforsch C Biosci), vol. 62, no. 7-8, pp. 507-513, 2007. 